\title{
Aspects of basic management of offenders with mental disorders
}

\author{
Martin Humphreys
}

Mental disorder and mental illness are common. Delinquency, offending and offending behaviour are widespread. The two things therefore occur frequently together, but are not always necessarily causally linked (Humphreys et al, 1994). Access to appropriate psychiatric services and care does not depend solely upon the presence of disturbed behaviour or offending that is obviously directly related to symptoms or signs.

I will describe some basic issues in the management of offenders with mental disorder, concentrating on those who might be involved in criminal rather than civil proceedings. I will not cover areas that require more detailed description, such as personality disorder and the legal concept of psychopathy. Reference is made to the principles of mental health legislation that apply broadly to most UK jurisdictions.

\section{Influences on management}

A wide variety of factors may influence the management of offenders with mental disorder, including the antecedents of the individual; past psychiatric history, diagnosis and associated factors; and whether they have entered the criminal justice system - if so, which stage of it they have reached. Other important issues are the quality of local inter-agency relationships and the availability of services and access to them. There are people with mental disorder who have not committed an offence and never will, but who nevertheless require similar services to those who have. For some, however, the criminal justice system affords a means of access to psychiatric services (see Box 1).
Many of those suffering from some form of mental disorder who fall foul of the law may have committed relatively minor offences and are unlikely to require specialist secure provision or associated services (Barker et al, 1993). The spectrum of psychiatric disorder seen among offenders is broad, but skewed towards psychotic illness in those admitted to hospital, and severe personality disorder in some secure settings - but the principles of treatment are founded firmly in the clinical and scientific basis of general psychiatry. Any variation is usually related to the social context of the illness and its presentation; legal constraints and the nature of the therapeutic environment, or both; and, in some cases, the nature and degree of disturbed behaviour associated with the disorder.

\section{Diversion from the criminal justice system}

As a general principle, it has been accepted that offenders with mental disorders should receive care

Box 1. Offending and mental disorder

The vast majority of those suffering from a mental disorder or a mental illness have never committed an offence

Most offences committed by people with mental disorders are relatively minor

Access to psychiatric services for offenders with mental disorders does not depend upon offending resulting directly from psychiatric signs or symptoms

Martin Humphreys is Senior Lecturer in Forensic Psychiatry at the University of Birmingham and Honorary Consultant Forensic Psychiatrist at Reaside Clinic (Birmingham Great Park, Birmingham B45 9BE). He has a particular research interest in mental health law and statutory follow-up of offenders with mental disorders, as well as the clinical care and treatment of female prisoners with mental disorders. 
and treatment rather than punishment (Home Office, 1990), although difficulties have been identified in attempts to maintain that approach (Farrar, 1996). Efforts have been made to identify such individuals at the earliest point of contact with the criminal justice system and to deal with them accordingly, or advise on future management. Not all offenders with mental disorders should necessarily be removed from the criminal justice process as soon as they are identified. In some cases, diversion may not be appropriate.

Schemes for diversion from custody take a variety of forms (see Box 2). Some provide access for the police to mental health care professionals - so-called diversion at the point of arrest (Wix, 1994). In other forms, psychiatrists are available directly or indirectly to the courts (Joseph \& Potter, 1990; James et al, 1997). Screening for mental health-related problems may also take place on admission to prison (Hillis, 1993), and many establishments have a visiting psychiatrist.

\section{Diversion at the point of arrest}

Where this is available, individuals who have not been charged may be referred for psychiatric assessment. It is possible to deal with the patient informally or under the Mental Health Act. When there are charges, it may be necessary to recommend that an individual remains in custody despite the presence of evident mental abnormality, or even mental illness. This situation may arise where access to information and a more suitable environment in which to undertake a comprehensive assessment or placement in an appropriately secure setting are not immediately available. Diversion schemes should not be seen as having failed because the offender with mental disorder is not extricated immediately from the criminal justice system. Success depends upon integrated services being available for the identification and treatment of the individual with mental

Box 2. Offenders with mental disorder may be diverted from the criminal justice system

At the point of arrest

At the police station

At the time of first appearance in court

While on bail

By transfer to hospital

While on remand

Through a psychiatric disposal from court

By transfer to hospital while serving a sentence of imprisonment disorder in the police station, at the court, on remand or serving a term of imprisonment (Fig. 1).

\section{Court diversion}

In some areas, screening procedures have been set up where a community psychiatric nurse or other mental health care worker attends the court lock-up area daily to review Crown Prosecution Service and other papers relating to the alleged offence, to discuss detainees with custody staff and to make assessments. The court may have an on-call psychiatrist available, or regular psychiatric sessions where assessments can also be undertaken. Where the individual with mental disorder is bailed, the court may seek psychiatric advice, and reports and assessment can be undertaken on an informal basis. Reports may also be requested for those remanded in custody.

\section{Bail hostel for offenders with mental disorders}

In Birmingham, there is a specialised bail hostel for offenders with mental disorder. It is the only one of its kind in the country. It does not provide an alternative to hospital care for those who might require it, but allows for placement of individuals with mental disorders who might otherwise have had to be remanded in custody for lack of a suitable community address. Also, it provides a limited number of places for people with mental disorders on probation. It is run by the probation service and staffed 24 hours a day. There is regular input from a multi-disciplinary clinical team. As a national resource, it accepts referrals from all over England and Wales, but comes under considerable pressure for places (Geelan et al, 1999).

\section{The law}

Mental health legislation makes provision for the care of offenders with mental disorder and their movement from the criminal justice system to psychiatric care. A good knowledge and clear understanding of the law in relation to civil detention, as well as how it provides for those involved in criminal proceedings or in prison, is essential in the management of these patients. It enables the practitioner to advise on the most appropriate means of dealing with a case where involuntary measures are necessary, and to offer guidance to individuals or agencies who are less familiar with the Mental Health Act, such as the police, legal practitioners, probation officers and the courts and prisons (Fig. 2). 


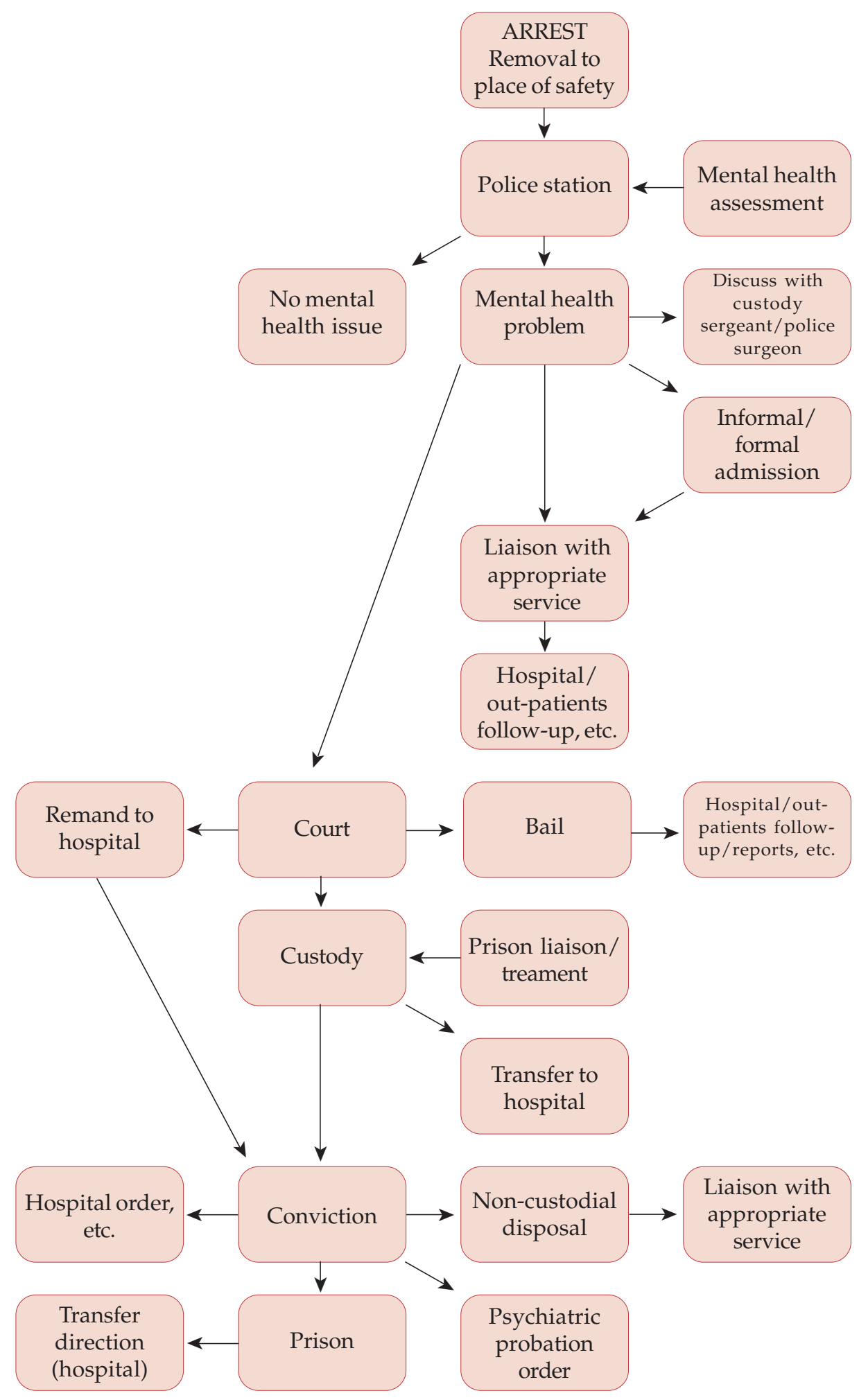

Fig. 1 Opportunities for diversion of people with mental disorders from the criminal justice system 


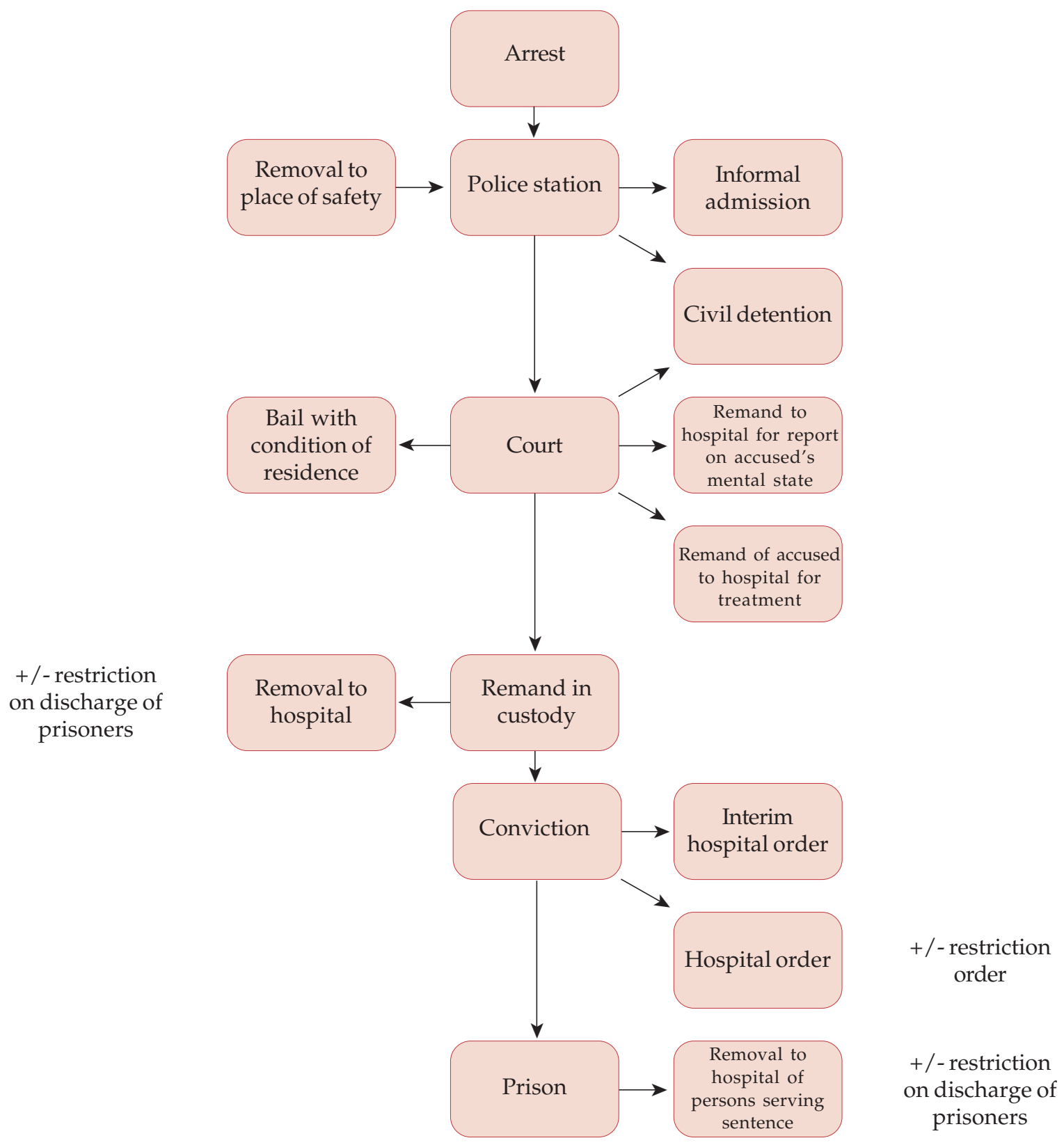

\section{Fig. 2 Statutory provision for treatment of patients involved in the criminal justice process}

\section{Transfer from prison} to hospital

It is possible to transfer a prisoner awaiting trial or sentencing to hospital. Similarly, a sentenced prisoner may also be moved to hospital when necessary. The exact requirements and procedures vary according to the jurisdiction (Briscoe et al, 1993).

\section{Treatment of prisoners under} the Mental Health Act

There is no right to treat prisoners for mental disorders against their will. One of the important effects of transfer of a prisoner to a psychiatric unit is to allow for treatment to be monitored and administered within the terms of the provision for 
consent to treatment in the relevant Mental Health Act.

\section{Offenders with mental disorder and the courts}

There are a variety of ways by which an individual with a mental disorder may be admitted to hospital under civil statutory provision (i.e. the Mental Health Act 1983) through the courts. They can be remanded there for the purpose of obtaining a report on their mental condition, or for treatment of a mental disorder, or, following conviction, be made subject to an interim hospital order or be detained on a hospital order with or without restrictions on discharge. Each of these requires specific conditions to be fulfilled and confers different powers. These have been described comprehensively by Briscoe $e t$ al (1993).

Remand to hospital and the interim hospital order are of practical and clinical importance and great value in cases where the diagnosis or prognosis is unclear, and there is uncertainty about whether a psychiatric disposal will ultimately be the correct one. They do not necessarily commit psychiatric services to longerterm involvement. Where appropriate, the patient may be returned to court and dealt with accordingly.

The mental state of the defendant may have an influence on court procedure. It may be necessary for a decision to be reached about whether the patient is fit to attend court, and if he or she is not, the relevant appropriate authority should be informed at the earliest possible time. Fitness to plead - broadly, an understanding of the charge and its meaning, the ability to distinguish between a plea of guilty and not guilty, and to follow court proceedings - may be compromised in cases of mental disorder and should be assessed carefully in all cases where the defendant has not yet pleaded. Legal insanity is rare and such a finding no longer leads to an automatic hospital order with restrictions on discharge, owing to the flexibility available under the Criminal Procedure (Insanity and Unfitness to Plead) Act 1991 (Bowden, 1995). The defence of diminished responsibility is available only in relation to charges for murder and depends upon the presence of "an abnormality of mind", as defined in Section 2 of the Homicide Act 1957. If successful, it results in conviction for manslaughter, again providing for flexibility in sentencing. There is no 'test' for diminished responsibility and it depends upon the evidence and the view of the court.

It is possible for the court to make an offender with mental disorder subject to a probation order with a condition of medical treatment (Harding, 1990). This may be helpful in certain circumstances, but is limited, for instance, in cases of drug or alcohol dependence, where self-motivation in treatment is important. The only sanction available is breach of the order. The most important consideration, given that there are no specific requirements, is that there is clear communication between all of those involved, particularly the patient, the psychiatrist and the supervising probation officer (Barry et al, 1993).

A hospital order made by the court generally only follows conviction for an offence that is punishable by imprisonment. Its effects are the same as those of a civil treatment order. A restriction order, which limits the powers of the Responsible Medical Officer $(\mathrm{RMO})$ in relation to leave, transfer and discharge from hospital, may be added where consideration has been given to the nature of the offence, the patient's history and likelihood of further future offending or serious harm to the public.

\section{Psychiatric reports}

The courts represent, define and administer the law. Their officers may or may not recognise the offender with a mental disorder when he or she appears before them - they are seldom expert in mental health matters or mental health law. In a case where someone clearly has a mental disorder or is thought to have, they may request or require urgent immediate psychiatric assessment or intervention, order reports, seek advice or hear evidence and, where appropriate, make a psychiatric disposal. They may choose not to make such a disposal, even in the face of rational and apparently overwhelming psychiatric evidence and specific recommendations that fulfil the necessary statutory requirements.

Management of offenders with mental disorders not infrequently involves the production of psychiatric reports for use in court, although their quality and value is variable (Chiswick, 1985). Nevertheless, when well-written, they are an important tool (Bluglass, 1995). Reports may be ordered by the judge or magistrate, or requested by the defendant's solicitor. As a general principle, they should address the specific circumstances of the individual concerned in terms of his or her legal status, and clinical history and present state. They should be clearly ordered and written for a lay readership (Rix, 1999). They should be based on a comprehensive psychiatric assessment with reference to relevant third-party information. At interview, it is important that the patient understands the purpose of the examination and appreciates that the usual principles of confidentiality do not apply in the same way as at any other consultation. It may be helpful to inform the interviewee that the information that is discussed may be included in the body of the report, which might in turn be read out in 
open court. It may also be important for the interviewer to remember that he or she may similarly be asked to justify the report's contents and conclusions.

Where recommendations for a psychiatric disposal are to be made, it is helpful to the courts if reference is made to the relevant legislation. It is important to address all necessary statutory criteria in each case and it may be expedient to employ the exact form of words used in the particular section of the Act.

\section{Offenders with mental disorder in prison}

There are substantial numbers of offenders with mental disorders in prison (Gunn et al, 1991; Davidson et al, 1995; Brooke et al, 1996). Their identification depends upon discipline staff, hospital or nurse officers, the prison medical officer or the visiting psychiatrist. A prisoner with a mental disorder is entitled to receive treatment for his or her condition, on an informal basis. He or she can be detoxified from alcohol or drugs, receive counselling and support or whatever form of psychological intervention might be appropriate - although these are often of limited availability and scope. Psychotropic medication may be prescribed, but may be given only with consent. In certain circumstances, the need may arise to administer medication in an emergency, but this should not be done repeatedly, and if it seems likely that this may become necessary, urgent transfer to hospital should be considered.

\section{Suicide and self-harm}

One of the major concerns and preoccupations in the care of individuals with mental disorder and others within prisons is the prevention of self-harm and suicide (Dooley, 1990). This is a problematic area where the needs of the distressed and disturbed individual are potentially seriously compromised and at odds with those of the institution. Suicide prevention strategies in prisons are still relatively crude and contrast markedly with those used in the care of potentially suicidal patients in hospital. Where suicidal thoughts or self-injurious behaviour are not clearly associated with a particular diagnosis or are not amenable to psychiatric or psychological intervention, it may be possible only to advise on simple measures such as: levels of observation; the need for the vulnerable individual to be in association with other people and in contact with organisations such as the Samaritans; or the use of 'listener' schemes, where volunteer prisoners take on a supportive role. Institutional practice may dictate the way in which cases are managed. Prisons maintain a low threshold for the identification of the potential for self-harm, but have a limited capacity to deal with such situations. Prisoners at risk tend to be placed in single-cell accommodation, sometimes in strip conditions. They are isolated from others. For many, this compounds feelings of hopelessness and despair. The psychiatrist's role may be confined to identifying and treating remediable mental disorder, but it should also include educating prison staff and seeking to influence institutional procedure.

\section{Treatment}

The range of treatments for offenders with mental disorders is similar in most ways to those for nonoffender patients. There may be limits to what is available, for instance, in prison (see above), and there are some more particular forms of therapy that may apply (see Box 3). Longer-term psychotherapeutic interventions may be appropriate in settings such as a special hospital or an out-patient unit for those with a personality disorder. Sex offender treatment programmes involving group and individual components may be helpful for both out-patients and inpatients. Anger management can be of value even where there is no psychiatric diagnosis as such. Cognitive-behavioural therapy is gaining increasing importance for patients with treatment-resistant psychotic illnesses, a group which may be overrepresented in forensic units.

Compliance, particularly with drug treatment, is an extremely important consideration. This is particularly so where offending behaviour is intimately linked to relapse and specific symptoms. Careful drug selection and patient education are central. The most appropriate agent should be selected with due regard to potential unwanted effects. In looking at dose reduction in any setting, consideration must be given to the potential risks and benefits to patients' health, but also to their own safety and that of those

\section{Box 3. Treatment}

Care in a secure environment

Psychotropic medication with due regard to the need for scrupulous future compliance

Long-term psychotherapy for personality disorder

Cognitive-behavioural therapy for 'voices'

Sex offender treatment programmes

Anger management

Family intervention/victim support

Intensive community follow-up/support 
around them in the event of relapse. Non-compliance with medication may be a risk factor, in relation not only to re-emergence of symptoms, but also serious violence (Zito Trust, 1996).

\section{Risk assessment and management}

Recently in health care services as a whole, and particularly in psychiatry, risk assessment and management have become an industry. There is a growing literature including review (Coid, 1996), research (Buchanan, 1997) and practical guidance (Moore, 1996). There is still a pressing need for investigation of specific factors that predict future behaviour among those suffering from mental disorder. Attempts to predict potential adverse future events and to effect change are based upon the availability of information providing a comprehensive clinical history and an understanding of past episodes, as well as an appreciation of the need for communication with others, including the patient. An understanding of the fact that risk is not an all-or-nothing phenomenon is important (Royal College of Psychiatrists, 1996). Risk assessment and management of offenders with mental disorders is the shared responsibility of all those involved in their care and treatment. It is a day to day activity and not the preserve of specialist services. Risk assessment is not a straightforward process with a simple mathematical formula giving a guaranteed outcome figure. It is based upon high standards of sound clinical practice. Risk management at its most simplistic involves recognising early indicators of change and providing suitable interventions. Overshadowing them both is the fact that, sometimes, serious adverse events are not predictable or preventable.

\section{Multi-disciplinary working and multi-agency liaison}

Effective multi-disciplinary teamwork is central to the management of offenders with mental disorders at almost every stage of their care and treatment (Burrow, 1994). This should be underpinned by agreed, clinically-oriented operational policies that can be revised or modified according to circumstances.

The composition of a multi-disciplinary team may depend upon resources, but stability and a clear team strategy are particularly important in the management of patients who may be required to remain in contact with psychiatric services for many years. Trust and quality of relationships may be central to successful relapse prevention and reduction in reoffending or other forms of disturbed behaviour (Brockman \& Humphreys, 1998). Consistency of approach facilitates good communication, which has been identified repeatedly as the area in which failure has contributed to the occurrence of adverse events in the case of some people with mental illness (Zito Trust, 1996). Good multi-disciplinary teamwork depends on regular review of clinical practice and individual professional skills and the team's capacity for communication - good inter-relationships between its members and unity of purpose (Griffin, 1989).

Working with other agencies to promote the cause of offenders with mental disorders and their needs may be challenging. It raises issues of professional boundaries and confidentiality. It is, nevertheless, a vital part of effective management to foster and maintain links with the police, probation services, courts and prisons. Regular meetings with representatives from relevant bodies can improve relationships and dispel myths.

\section{Security as a component of treatment}

For certain groups of offenders with mental disorders, care in secure conditions is an important part of treatment. Appropriate placement is often a central issue. Patients may sometimes require physical security depending upon their mental state, and, perhaps more importantly, risk of absconding or serious offending behaviour. Admission criteria to secure facilities vary and procedures may depend upon central legal or administrative issues (Dent, 1997). They are more often matters of local policy and clinical judgement. Many offenders with mental disorders need the 'internal' security associated particularly with a higher nursing staff : patient ratio, which increases the opportunity to build effective therapeutic relationships. A secure environment, with staff trained in techniques for de-escalation of violence and the proper procedures of control and restraint, may enable a period of treatment-free assessment to clarify diagnostic or other issues. Lastly, there is still an urgent need for mid- to long-term, low- to mediumsecure facilities for certain offenders with mental disorders and others who require similar care.

\section{Restricted patients}

In certain circumstances, the court may make a restricted hospital order. Thereafter, applications for change of placement or leave status must be approved by the Secretary of State.

Restricted patients may be absolutely discharged if they no longer fulfil criteria for detention. They may, however, be granted a conditional discharge, in which case they remain liable to recall to hospital. In those circumstances, they require named medical and social supervisors, usually a consultant psychiatrist and 
social worker, respectively. The conditions may include, for example, a specified place of residence. In practice, the patient may be recalled to hospital for a variety of possible reasons, including concerns over potential or actual re-offending, deterioration in mental state or non-compliance with treatment. Psychiatric and social supervisors are required to write regular reports on conditionally discharged patients. Restricted hospital orders have the advantage of providing for potentially longer-term statutory follow-up of patients who have committed often serious offences, who might otherwise have been difficult to engage with psychiatric services (Humphreys et al, 1998).

\section{Conclusions}

The care needs of offenders with mental disorder can be complex and may change with time. Their management depends upon an understanding of the relationship between mental disorder and offending behaviour, as well as the criminal justice process. Correct placement, with the appropriate multi-disciplinary and multi-agency involvement in treatment and follow-up, is central.

\section{References}

Barker, A., Forshaw, D., Gudjonsson, G., et al (1993) Ninetyfive percent of crime. In Forensic Psychiatry. Clinical, Legal and Ethical Issues (eds J. Gunn \& P. Taylor), pp. 567-598. Oxford: Butterworth Heinemann.

Barry, M., Gudjonsson, G., Gunn, J., et al (1993) The mentally disordered offender in non-medical settings. In Forensic Psychiatry. Clinical, Legal and Ethical Issues (eds J. Gunn \& P. Taylor), pp. 772-793. Oxford: Butterworth Heinemann.

Bluglass, R. (1995) Writing reports and giving evidence. In Practical Forensic Psychiatry (eds D. Chiswick \& R. Cope), pp. 134-163. London: Gaskell.

Bowden, P. (1995) Psychiatry and criminal proceedings. In Seminars in Practical Forensic Psychiatry (eds D. Chiswick \& R. Cope), pp. 106-133. London: Gaskell.

Briscoe, O., Carson, D., D'orban, P., et al (1993) The law, adult mental disorder, and the psychiatrist in England and Wales. In Forensic Psychiatry. Clinical, Legal and Ethical Issues (eds J. Gunn \& P. Taylor), pp. 21-117. Oxford: Butterworth Heinemann.

Brockman, B. \& Humphreys, M. S. (1998) Criminal Evidence (Amendment) Act 1997. Compromised ethics: consequences of compulsory DNA sampling from psychiatric patients. Journal of Forensic Psychiatry, 9, 245-247.

Brooke, D., Taylor, C., Gunn, J., et al (1996) Point prevalence of mental disorder in unconvicted male prisoners in England and Wales. British Medical Journal, 313, 15241527.

Buchanan, A. (1997) The investigation of acting on delusions as a tool for risk assessment in the mentally disordered. British Journal of Psychiatry, 170 (suppl. 32), 12-16.

Burrow, S. (1994) A source of conflict at the heart of the team. The role of the forensic multi-disciplinary care team. Psychiatric Care, 1, 192-196.

Chiswick, D. (1985) Use and abuse of psychiatric testimony. British Medical Journal, 290, 975-977.
Coid, J. W. (1996) Dangerous patients with mental illness: increased risks warrant new policies, adequate resources, and appropriate legislation. British Medical Journal, 312, 965-966.

Davidson, M., Humphreys, M. S., Johnstone, E. C., et al (1995) Prevalence of psychiatric morbidity among remand prisoners in Scotland. British Journal of Psychiatry, 167, 545-548.

Dent, S. (1997) The Home Office Mental Health Unit and its approach to the assessment and management of risk. International Review of Psychiatry, 9, 265-271.

Dooley, E. (1990) Prison suicide in England and Wales, 1972 87. British Journal of Psychiatry, 156, 40-45.

Farrar, M. (1996) Government policy on offenders with mental disorder and its implementation. Journal of Mental Health, 5, 465-474.

Geelan, S., Griffin, N. \& Briscoe, J. (1999) A profile of residents at Elliot House, the first approved bail and probation hostel for mentally disordered offenders. Health Trends, 30, 102-105.

Griffin, N. V. (1989) Multiprofessional care in forensic psychiatry. Realities and constraints. Psychiatric Bulletin, $13,613-615$

Gunn, J., Maden, A. \& Swinton, M. (1991) Treatment needs of prisoners with psychiatric disorders. British Medical Journal, 303, 338-341.

Harding, J. (1990) The probation service. In Principles and Practice of Forensic Psychiatry (eds R. Bluglass \& P. Bowden), pp. 1397-1405. Edinburgh: Churchill Livingstone.

Hillis, G. (1993) Diverting tactics. Nursing Times, 89, 24-27. Home Office (1990) Provision for Mentally Disordered Offenders. Circular 66/90. London: HMSO.

Humphreys, M. S., Johnstone, E. C. \& Macmillan, J. F. (1994) Offending among first episode schizophrenics. Journal of Forensic Psychiatry, 5, 51-61.

- Kenney-Herbert, J. P. \& Gray, C. (1998) Restricted hospital orders: a survey of forensic psychiatrists' practice and attitudes to their use. Journal of Forensic Psychiatry, 9, 173-180.

James, D., Cripps, J., Gilluley, P., et al (1997) A court-focused model of forensic psychiatry provision to central London: abolishing remands to prison? Journal of Forensic Psychiatry, 8, 390-405.

Joseph, P. \& Potter, M. (1990) Mentally disordered homeless offenders: diversion from custody. Health Trends, 2, 51-53.

Moore, B. (1996) Risk Assessment: A Practitioner's Guide to Predicting Harmful Behaviour. London: Whiting \& Birch.

Rix, K. J. B. (1999) Expert evidence and the courts: 2. Proposals for reform, expert witness bodies and 'the model report'. Advances in Psychiatric Treatment, 5, 154-160.

Royal College of Psychiatrists' Special Working Party on Clinical Assessment and Management of Risk (1996) Assessment and clinical management of risk of harm to other people. Council Report CR53. London: Royal College of Psychiatrists.

Wix, S. (1994) Keeping on the straight and narrow. Diversion at the point of arrest. Psychiatric Care, July/August, 102104 .

Zito Trust (1996) Learning the Lessons (2nd edn). London: Zito Trust.

\section{Multiple choice questions}

1. Most offenders with mental disorders:

a have committed serious offences

b suffer from a personality disorder

c commit offences that are related directly to mental symptoms

d do not require specialist forensic services

e should receive treatment rather than punishment. 
2. Diversion from the criminal justice system:

a depends upon good inter-agency working

$\mathrm{b}$ is available everywhere as a comprehensive service

c can involve mental health care professionals from different disciplines

$\mathrm{d}$ is available through one of several specialised bail hostels throughout the country

e prevents imprisonment of offenders with mental disorders.

3. Current mental health legislation may:

a allow the detention of offenders with mental disorder under civil sections

b provide for compulsory treatment of prisoners with mental disorder serving a sentence

c facilitate the transfer to hospital of prisoners awaiting trial or sentencing suffering from psychopathic disorder

d permit a restriction order to be imposed by the court which limits the powers of the RMO

e provide for residence in hospital as a condition of bail.

4. Psychiatric court reports:

a are always requested by the defendant's solicitor

b must specify the nature of the disorder where a hospital order is recommended

c should avoid quoting word-for-word from the relevant legislation d should never contain clinical information

e are confidential medical documents.

5. In prison:

a there are relatively few individuals with mental disorder

b psychotropic medication may not be routinely administered without consent

c individuals with mental disorder will always be placed in a hospital wing

d suicide prevention policies are similar to those that exist in the health service

e those deemed at risk of self-harm may be placed in strip cells.

MCQ answers

\begin{tabular}{|c|c|c|c|c|}
\hline 1 & 2 & 3 & 4 & 5 \\
\hline F & a $\mathrm{T}$ & a $\mathrm{T}$ & a $F$ & a $F$ \\
\hline F & b F & b F & b $\mathrm{T}$ & b $T$ \\
\hline $\mathbf{F}$ & c $\quad T$ & c $F$ & c $F$ & c $\quad F$ \\
\hline $\mathrm{T}$ & d F & d $T$ & d F & d $F$ \\
\hline $\mathrm{T}$ & e $F$ & e $F$ & e $F$ & e $T$ \\
\hline
\end{tabular}

\section{Commentary}

\section{Tim Exworthy}

Dr Humphreys is right to emphasise that the majority of offenders with mental disorder have not committed serious offences (conversely, a number of general psychiatric patients are admitted to hospital after incidents in the community which, in different circumstances, might have attracted official attention) and that the principles of treatment and management are the same as for patients in general psychiatry. However, psychiatric assessment of more serious offending does call for careful consideration of additional issues, such as 'psychiatric defences' to criminal charges (including fitness to plead, insanity, automatisms, and in cases of charges of murder, diminished responsibility) and the role of security in their management.

The need for the appropriate degree of security during the admission of some patients is addressed in the guiding principles of the Code of Practice to the Mental Health Act 1983 (Department of Health \& Welsh Office, 1999). This states that people to

Tim Exworthy is a consultant forensic psychiatrist at Redford Lodge Hospital (15 Church Street, Edmonton, London, N9 9DY) having previously been a consultant at Broadmoor Hospital since 1995. He is also Honorary Senior Lecturer in the Department of Forensic Psychiatry at the Institute of Psychiatry, London. His main research interest is in mental health law, but he has also published on court-based psychiatric schemes and service provision in forensic psychiatry. 